\title{
OBITUARY
}

\section{HARALD CRAMÉR}

25th September 1893-5th October 1985

Harald Cramér, the well-known scientist, passed away on October 5th, 1985 some weeks after his 93rd birthday. His intellect was clear until the end.

Cramér took part in the planning of ASTIN (Actuarial Studies In Non-life insurance) before and during the international congress of actuaries in New York 1957. He gave valuable support to its foundation according to the program which was developed by a group of far-seeing actuaries and research workers.

At the $A S T I N$ Colloquium at Rättvik in Sweden in 1961 Cramér as an invited guest presented an introductory lecture on general aspects of non-life actuarial research.

Harald Cramér was born in Stockholm and studied mathematics and chemistry at the Stockholm University. In 1917 he presented a thesis in mathematics with application to the distribution of prime numbers. Marcel Riesz, one of the two famous Hungarian brothers who both became professors in mathematics-one in Sweden and the other in U.S.A.-stimulated Cramér's research in actuarial mathematics and the theory of probability. In 1920 he became the actuary of the mutual life insurance company Svenska Lif, and 1928 of the Swedish reinsurance company Sverige. In the early twenties we find several papers by Cramér in Skandinavisk Aktuarietidskrift (SAT). An early one was published 1923 in German, “Das Gesetz von Gauss und die Theorie des Risikos". In 1928 he published "On the Composition of Elementary Errors" in two parts, one with mathematical deductions and the other with statistical applications. Cramér's "Sannolikhetskalkylen och Några av dess Användningar" of 1927 became a classic for Swedish students in the calculus of probability. An edition in English "The Elements of Probability Theory" was published in 1955.

Cramér published in SAT 1926 a review of 22 pages on Filip Lundberg's publications in collective risk theory, with applications to life and sickness insurance. These studies as well as Cramér's review were published in Swedish. Without this review, containing useful explanations in common mathematical language it is doubtful if Lundberg's works would have been correctly understood.

After Cramér's review and his survey on collective risk theory, "On the Mathematical Theory of Risk" (Skandia 1930), there followed in the early 30's a series of papers by Swedish actuaries about collective risk theory.

Harald Cramér was appointed professor at Stockholm's Högskola in 1929, and became the head of the Institute of Insurance Mathematics and Mathematical Statistics. The professorship and the institute were sponsored by the Swedish life insurance companies. In the time before the war the research focused on the collective risk theory in particular, and on the theory of stochastic processes, as defined by Kolmogoroff and Khinchine, in general. Willy Feller was one of the collaborators at the institute during the years 1934-1939. Several of us Swedish members of the Astin group have been either researchers or students at Cramér's

ASTIN BULLETIN Vol. 16, No. 1 
institute. We fell deep respect not only for his outstanding scientific qualities but also for his character and humanity.

By his magnum opus "Mathematical Methods of Statistics" of 1945 Harald Cramér formulated a scientific program of statistical theory. In his publication of 1955 on collective risk theory included in the Jubilee volume of the insurance company Skandia, Cramér gives a complete mathematical theory for calculating ruin probabilities.

Harald Cramér was the President of the Swedish Society of Actuaries in 1935-1964 and afterwards its Honorary President. He was chief editor of SAT 1940-1963. He gave lectures at universities all over the world and continued to lecture until 90 years of age. At Kungl. Vetenskapsakademien (Royal Swedish Academy of Sciences) Harald Cramér gave a fascinating lecture on the subject "Sixty Years in the Service of Probability Theory" as late as in November 1983, after attained 90 years of age. He became Honorary Doctor at Princeton, Copenhagen, Stockholm, Helsingfors, Edinburgh, Paris and Calcutta.

O. LUNDBERG

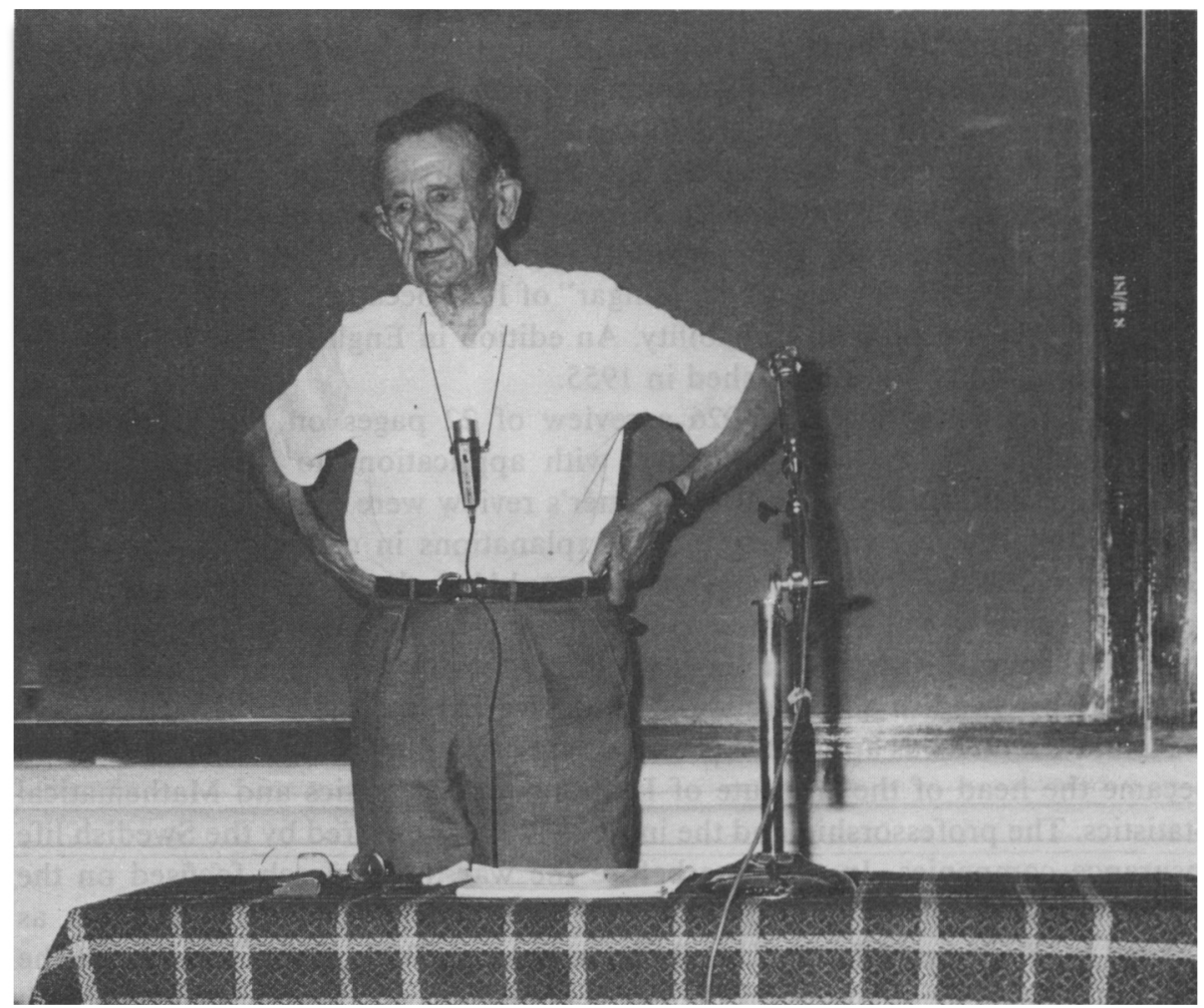

Photograph shows Harald Cramér giving a lecture at the Calcutta University in 1977 when receivıng the Honorary Doctor degree 